\title{
Effect of stem cell application on Asherman syndrome, an experimental rat model
}

\author{
Sevtap Kilic • Beril Yuksel • F. Pinarli • A. Albayrak • \\ B. Boztok $\cdot$ T. Delibasi
}

Received: 14 January 2014 / Accepted: 1 June 2014 / Published online: 29 June 2014

(C) Springer Science+Business Media New York 2014

\begin{abstract}
Purpose We evaluate the effect of stem cells to induce endometrial proliferation and angiogenesis on Asherman Syndrome (AS).

Methods The experimental study was performed in stemcell research laboratory. Forty Wistar-Albino rats were divided according to groups. In group1 $(n=10)$ to establish the model; trichloroacetic acid was injected to right uterine horn. Two weeks later, intrauterine synechia was confirmed. In group2 $(n=10), 2$ weeks later, $2 \times 106$ mesenchymal stem cells (MSC) were injected into right uterine horn followed by three intraperitoneal injections of MSCs. In group3 $(n=10)$, daily oral estrogen was initiated on the second week. In group4 $(n=10)$, MSC injections and oral estrogen was given together. The amount of fibrosis, vascularisation, inflammation and immunohistochemical staining with vascular endothelial growth factor (VEGF), proliferating cell nuclear antigen (PCNA) and Ki-67 were evaluated in the uterine tissues.
\end{abstract}

Presented at 69th American Society of Reproductive Medicine (ASRM) Annual Meeting held conjoint with IFFS Boston Convention \& Exhibition Center, Boston, Massachusetts, USA, October 12 to 17.

Capsule Stem Cell Application for Uterine Synechia

S. Kilic $(\bowtie)$

Kastamonu School of Medicine, Hacettepe University, Süleyman bey sokak 29/10, Maltepe, Ankara 06420, Turkey

e-mail: sevtapkilic@gmail.com

B. Yuksel

Department of Assisted Reproductive Technologies, Dumlupinar University School of Medicine, 3222. Cadde 9b/12, Yasamkent,

Ankara, Turkey

F. Pinarli $\cdot$ B. Boztok $\cdot$ T. Delibasi

Yildirim Beyazit Research Hospital, Adacell Laboratory, Pancreas

Islet Cell Research Center, Ankara, Turkey

A. Albayrak

Pathology Department of Numune Research and Educational

Hospital, Istanbul, Turkey
Results In all treatment groups; fibrosis decreased but vascularisation and immunhistohemical stainings increased in the experimental side. The amount of fibrosis, vascularisation, Ki67 and PCNA scores were similar between group2 and 3. In group4, comparing to group2, less fibrosis but more Ki-67, PCNA and VEGF staining was observed.

Conclusion Stem cells, when added to estrogen, are a highly effective alternative to induce regeneration of endometrium in Asherman Syndrome therapy.

Keywords Intrauterine adhesion · Intrauterine synechia · VEGF $\cdot$ PCNA $\cdot$ Ki-67

\section{Introduction}

Asherman Syndrome (AS) is defined as intrauterine adhesions usually occurring after curettage or any uterine surgery including myomectomy, hsysteroscopic resection of uterine septum, laparotomic metroplasty or radiation. It can also be seen after postpartum or post cesarean section [1]. But most of the cases are related to curettage for pregnancy complications, such as missed or incomplete abortion, retained placental remnants or postpartum hemorrhage [2].

The syndrome can reveal itself in a wide spectrum of clinical presentations. Menstrual disorders, chronic pelvic pain, recurrent pregnancy loses and infertility are some of these clinical problems frequently associated with AS. Menstrual disorders are often expressed as amenorrhea, hypomenorrhea, or dysmenorrhea depending on the extent of disease and amount of adhesions in the uterine cavity [3].

The leading pathologic problem in AS is the avascular fibrous connective tissue bands with or without glandular tissue [4]. Hysteroscopic lysis of these adhesions is the main method of treatment. The aim of the surgery is to restore the shape of the uterine cavity [5]. In some instances, such as 
dense scar tissue and difficult entry to the cervix, a simultaneous laparoscopic guidance may be required to provide safety and reduce the risk of uterine perforation [3].

Most surgeons use an intrauterine device (IUD) and follow treatment with sequential estrogen and progesterone therapy to promote endometrial healing. But the potential problems of high dose systemic estrogen and the inefficiency of IUDs in the latest reports enforced researches to continue the investigation for new treatment options.

The popularity of stem cells has been rising in the last decade. Stem cells are cells found in all multicellular organisms, which can divide and differentiate into specialized cell types and can self-renew themselves. Isolation, proliferation and differentiation of these cells can be effective in diagnosis and treatment of a wide spectrum of diseases. Ischemic vascular diseases, metabolic storage diseases, hemoglobinopathies, malignancies, neurologic disorders, autoimmune diseases and preservation of fertility are some common therapeutic applications [6]. In this study, we aimed to evaluate the effect of stem cells to induce endometrial proliferation and angiogenesis on an experimental Asherman Syndrome model.

\section{Material-method}

\section{Experimental protocol}

An approval from Institutional Review Board and Institutional Animal Care and Use Committee was taken prior to study. Before starting the study, 2 wistar albino rats were used to establish the experimental model. Under ketamine $(50 \mathrm{mg} / \mathrm{kg})$ anesthesia, the abdomen was shaved and prepared with iodophors solution. The uterine horns were exposed by an abdominal midline incision and a piece of gauze was used to wrap right uterine horn to prevent abdominal viscera. To establish the experimental model, $0.1 \mathrm{ml}$ of trichloroacetic acid (IL $33 \circledR$, Istanbul Ilac Sanayi ve Ticaret AS, Umraniye, Istanbul, Turkey) was injected into right uterine horn. Left horn was set as control. Two weeks later, intrauterine synechia was confirmed by pathology (Fig. 1a, b).

After establishing and confirming the model, the study was started with 40 wistar albino rats. The rats were cycle synchronized according to their vaginal smear analysis and divided into four groups. Group $1(n=10)$ was named as Asherman group, in which the experimental protocol was performed. In group2 $(n=10)$, at the end of second week, a re-laparotomy was performed and $2 \times 106$ adipose tissue derived mesenchymal stem cells (MSCs) were injected into right uterine horn followed by three consecutive intraperitoneal injections of MSC with 5-day intervals. In group3 $(n=10)$, daily $0.1 \mathrm{mg} / \mathrm{kg}$ oral estrogen (Estrofem ${ }^{\circledR}, 2 \mathrm{mg}$, NovoNordisk Pharmaceuticals, A/a, Denmark) was initiated on the second week of experiment. The dosage was determined on the basis of previous studies [7]. In group4 $(n=10)$, MSC injections and oral estrogen was given together. During these procedures, in each group some of the rats died due to different reasons (infection, bowel obstruction, incisional injury) (Fig. 1c). At the end of 8 weeks, rats were sacrificed and bilateral uterine horns were resected.

The specimens were evaluated under light microscopy with Hematoxylene-Eosin (H\&E). The immunhistochemical evaluations for vascular endothelial growth factor (VEGF), proliferating cell nuclear antigen (PCNA) and Ki-67 were also performed.

Preparation of adipose tissue derived mesencyhmal stem cell

The adipose tissue culture protocol was based on Fried and Moustaid-Moussa [8]. The adipose tissue explants, gathered from inguinal region of two male rats, were transported from the operating room to the laboratory in a transport buffer containing phosphate buffered saline (PBS), $5.5 \mathrm{mM}$ glucose and $50 \mathrm{~g} / \mathrm{ml}$ gentamicin at room temperature. The following procedures were carried out under a laminar flow hood using sterile equipments. Immediately upon arrival, the tissue was transferred to a Petri dish containing $3 \mathrm{ml}$ of PBS and was finely minced in 10-20 $\mathrm{mg}$ pieces using scissors. The tissue pieces were extensively washed with $10 \mathrm{ml}$ of PBS over a filter containing sterile cotton bandage fabric. Thereafter, the tissue pieces were transferred to a $25 \mathrm{~cm}^{2}$ culture flask containing $1 \mathrm{ml}$ of PBS and were gently shaken for a short period. Adipose tissue pieces were incubated at $37{ }^{\circ} \mathrm{C}$ and $5 \% \mathrm{CO} 2$ and cultured in the MSC medium,co ntaining DMEM-LG (Invitrogen), $20 \%$ fetal bovine serum (FBS; Biological Industry), $100 \mathrm{U} / \mathrm{mL}$ penicillin, $100 \mathrm{mg} / \mathrm{mL}$ streptomycin (Biological Industry) and $20 \mathrm{ml} / \mathrm{L} \mathrm{L}$-Glutamin. The culture media was exchanged every 3 days and finally when the colony forming unit fibroblasts (CFU-Fs) became visible and reached more than $70 \%$ confluence on day 16 ; the cells were detached by using $0.25 \%$ trypsin in $0.02 \%$ ethylene-diamino-tetraacetic acid (EDTA) and subcultured on a standard culture dish. After the third passage, the cells produced were suspended and were identified once more with flow cytometry (FACS Aria III, Becton, Dickinson and Company, USA) using mesenchymal stem cell surface determinants [CD11b/c (-), CD45 $(-)$, CD90 (+), CD44 (+), CD49(+)] (Fig. 2g).

Thereafter, in order to identify MSC characterization, the cells were cultured in adipocyte, chondrocyte and osteocyte differentiation mediums. To define the cells; the staining with oil red (Diagnostic BioSystem, Pleasanton, USA) for the adipocytes, Alcian blue (Diagnostic BioSystem, Pleasanton, USA) for the chondrocytes and Von Kossa (Diagnostic BioSystem, Pleasanton, USA) for the osteocytes were done. 
Fig. 1 a-b Intrauterine synechia within the cavity after the establishment of experimental protocol (Arrows indicate the synechia inside the uterine cavity). c Consort diagram of rats during the experiment

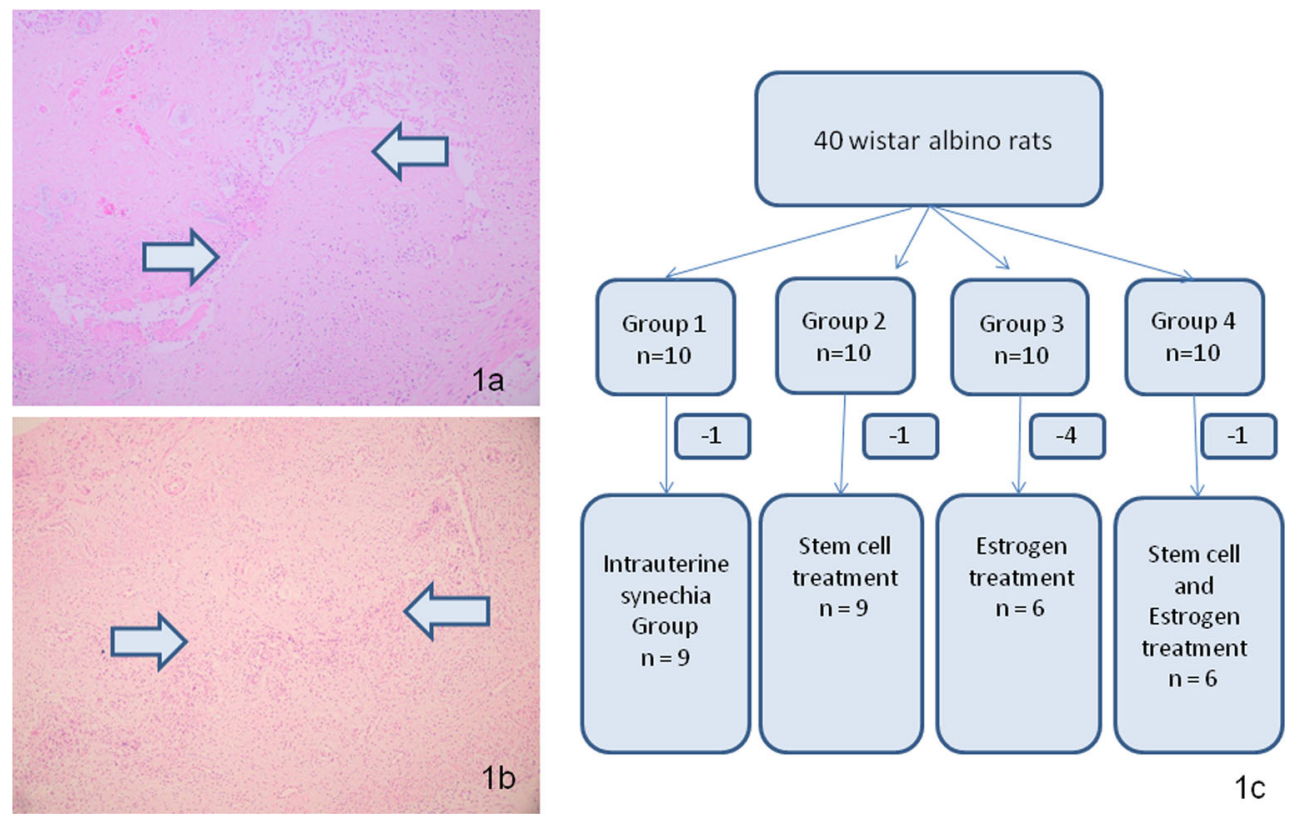

5-bromo-2'-deoxyuridine (BrdU) staining of adipose tissue derived mesencyhmal stem cell

To label MSCs in vitro, $10 \mu \mathrm{l}$ of BrdU solution ( $1 \mathrm{mM}$ BrdU in $1 \times$ Dulbecco's PBS, BD Pharmingen) was carefully added for each $\mathrm{ml}$ of tissue culture medium. The cell culture density was $2 \times 106$ cells $/ \mathrm{ml}$. The treated cells were incubated for $2 \mathrm{~h}$ before their administration. $2 \times 106 \mathrm{MSCs}$ were injected into right uterine horn followed by three consecutive intraperitoneal injections with 5-day intervals. To show the presence of
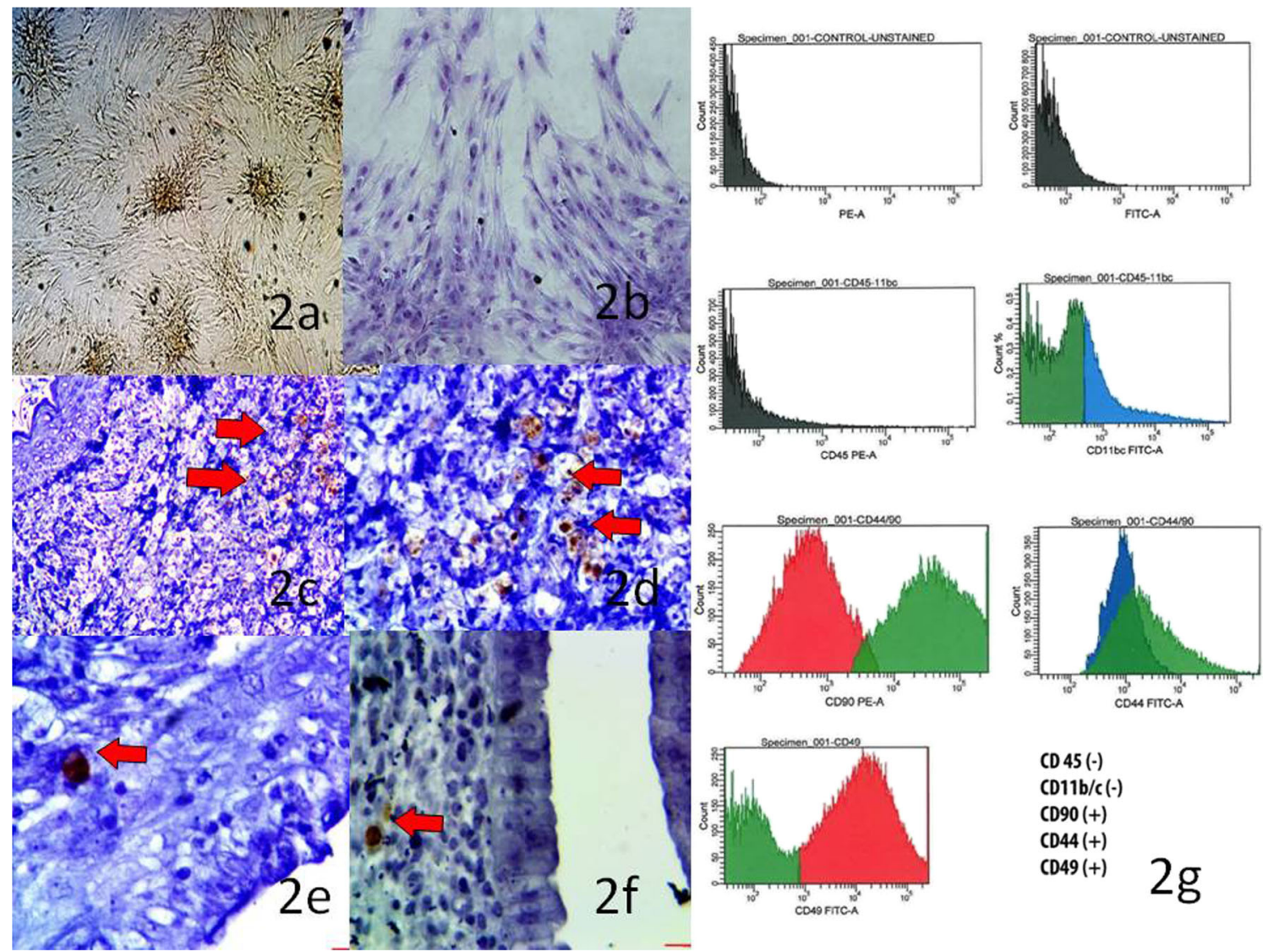

Fig. 2 a MSC culture (CFU-Fs; X10) b MSCs with Giemsa staining (X20) c-f BrdU immunostaining in the uterine tissue sections of group 2 and group 4 (Arrows indicate the BrdU positive cells). $\mathrm{g}$ Adipose tissue derived mesenchymal stem cell identification with flow cytometry 
BrdU $(+)$ cells in the uterine tissues; formalin-fixed, paraffinembedded tissues were prepared as $4 \mathrm{~mm}$ thick slides and deparaffinized twice in xylene for 5 min each. The slides were transferred to $100 \%$ and $95 \%$ alcohol and two changes for 3 min were performed each time. Endogenous peroxidase activity was blocked with $3 \% \mathrm{H} 2 \mathrm{O} 2$ in PBS for $10 \mathrm{~min}$. The slides were rinsed 3 times for 5 min each time in PBS. Then the sections were immunhistochemically stained with BrdU detection Kit (BD-Pharmingen) to show the presence of BrdU $(+)$ cells (Fig. 2c-f). To determine the percentage of $\mathrm{BrdU}(+)$ cells, they were counted in the $\mathrm{x}-\mathrm{y}$ plane at $40 \times$ magnification.

\section{Light microscopic evaluation}

After fixation with $10 \%$ formalin, the tissues were washed under running tap water for $24 \mathrm{~h}$ and dehydrated with 50, 60, $70,80,90,96$ and $100 \%$ concentrated ethanol. The specimens were then laid in a 1:1 ratio of immersion oil and absolute alcohol for $1 \mathrm{~h}$, followed by immersion oil overnight, for transparency. After the application of xylol, the specimens were made into paraffin blocks using a 1:1 xylol and paraffin mixture for $1 \mathrm{~h}$ and paraffin for $6 \mathrm{~h}$ in an incubator. $4 \mu \mathrm{m}$ thick sections were dehydrated and dyed with Hematoxylene-Eosin (H\&E) (According to application procedure of BioOptica Milano, ITALY).

The specimens were evaluated for fibrosis, inflammation and vascular proliferation; rated on a modified semiquantitative scale of $0-3$. The amount of fibrosis was scored as follows: 0 , no fibrosis; 1 , minimal, loose fibrosis; 2 , moderate fibrosis; and 3, dense fibrosis. Inflammation was scored as follows: 0 , no inflammation; 1 , presence of occasional lymphocytes and plasma cells; 2, presence of plasma cells, eosinophils and neutrophils; and 3, presence of many inflammatory cells and microabscesses. Vascular proliferation was scored as: 0 , no vascular proliferation; 1 , mild vascular proliferation; 2, moderate vascular proliferation; and 3; intense vascular proliferation [9].

Immunhistochemical evaluation

To demonstrate the stimulation and proliferation of endometrium; immunohistochemical studies with the proliferation markers, proliferating cell nuclear antigen (PCNA), Ki-67 and VEGF were performed. All specimens were fixed in $10 \%$ formalin and were dehydrated by immersion in a series of alcohol solutions of various concentrations, cleared in xylene and paraffin-embedded tissue sections. Briefly, $5 \mu \mathrm{m}$-thick sections were obtained using a microtome, transferred into adhesive slides, and dried at $60{ }^{\circ} \mathrm{C}$ for $30 \mathrm{~min}$. All slides $w$ ere de-paraffinized using xylene and then rehydrated in decreasing concentrations of ethanol. Antigen retrieval was performed using microwave heating (three times of $10 \mathrm{~min}$;
$10 \mathrm{mM}$ citrate buffer, pH6.0) after inhibition of endogenous peroxidase for $15 \mathrm{~min}$ ). The slides were incubated for $1 \mathrm{~h}$ with rabbit polyclonal antibodies to VEGF (1:100; Thermo scientific, USA), Kİ-67 (1:100; Thermo scientific, USA), PCNA (1:100; Thermo scientific, USA) at room temperature, then washed using PBS and then incubated with secondary antibody (Invitrogen, UK) for 15 min followed by PBS wash. Finally, the detection of bound antibody was accomplished using the avidinbiotin complex $(\mathrm{ABC})$ reagent for $20 \mathrm{~min}$ then PBS wash. A $0.1 \%$ solution of diaminobenzidine (DAB) (DAB, Thermo scientific, USA) was used for $5 \mathrm{~min}$ as a chromogen. Slides were counterstained with Mayer's hematoxylin for 5-10 $\mathrm{min}$. All histopathological examinations were performed by a designated pathologist experienced in rat histology, who was blinded to all relevant information regarding the specimens. Proliferating cell nuclear antigen (PCNA) and $\mathrm{Ki}-67$, the markers of the proliferative activity were semiquantitatively analyzed by choosing ten random fields. In each field, 100 epithelial cells were selected and viewed. The PCNA and Ki-67 indexes were expressed as percent of positive cells $[10,11]$.

To evaluate VEGF expression, the number of capillary vessels and proliferation cells was counted and averaged from at least 3 randomly selected fields under a magnification of $400 \times[12]$.

\section{Statistical analysis}

Statistical analysis was performed using SPSS for Windows release 15.0 (Chicago Inc., Chicago, IL). The calculation was expressed as mean and standard deviation for numerical data. The means were compared by Kruskall-Wallis and MannWhitney U tests. $p$ Values less than 0.05 were considered as statistically significant.

\section{Results}

First, when we looked at the labeled stem cells in the effected uterine side of rats; as expected, we did not observe any BrdU immunostaining in the uterine tissue sections of group 1 and group 3. But, we observed 4-6\% BrdU labeled cells in the uterine tissue sections of group 2 and group 4 (Fig. 2c-f).

When we looked at $\mathrm{H} \& \mathrm{E}$ stained preparates under light microscopy, we observed increased vascularisation and decreased fibrosis in all treatment groups when compared to group 1 (Fig. 3a-d). And when we looked at the immunhistochemical staining of PCNA, Ki-67 and VEGF which were identified by the presence of brown nuclear reactivity, we observed an increased staining index in the treatment groups when compared to group 1 (Fig. 3e-n). After light microscopic and immunohistochemical evaluation; we 


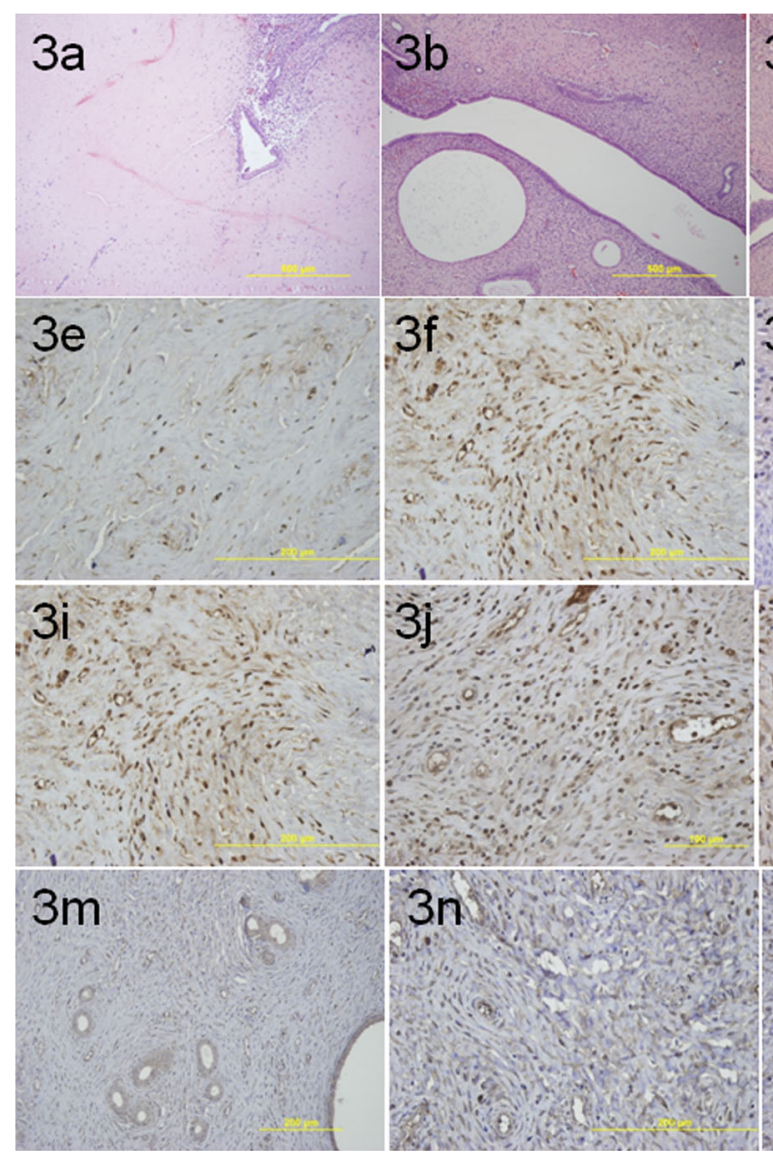

Fig. 3 a Light microscopic view of right uterine horn in intrauterine adhesion group (group 1). b Light microscopic view of right uterine horn in group 2. c Light microscopic view of right uterine horn in group 3. d Light microscopic view of right uterine horn in group 4. e The immunhistochemical staining of PCNA in group 1. f The immunhistochemical staining of PCNA in group 2. $\mathrm{g}$ The immunhistochemical staining of PCNA in group 3. $\mathbf{h}$ The immunhistochemical staining of PCNA in

saw that in all treatment groups; fibrosis decreased, vascular proliferation increased in the experimental side; when compared to group1 (Table 1).

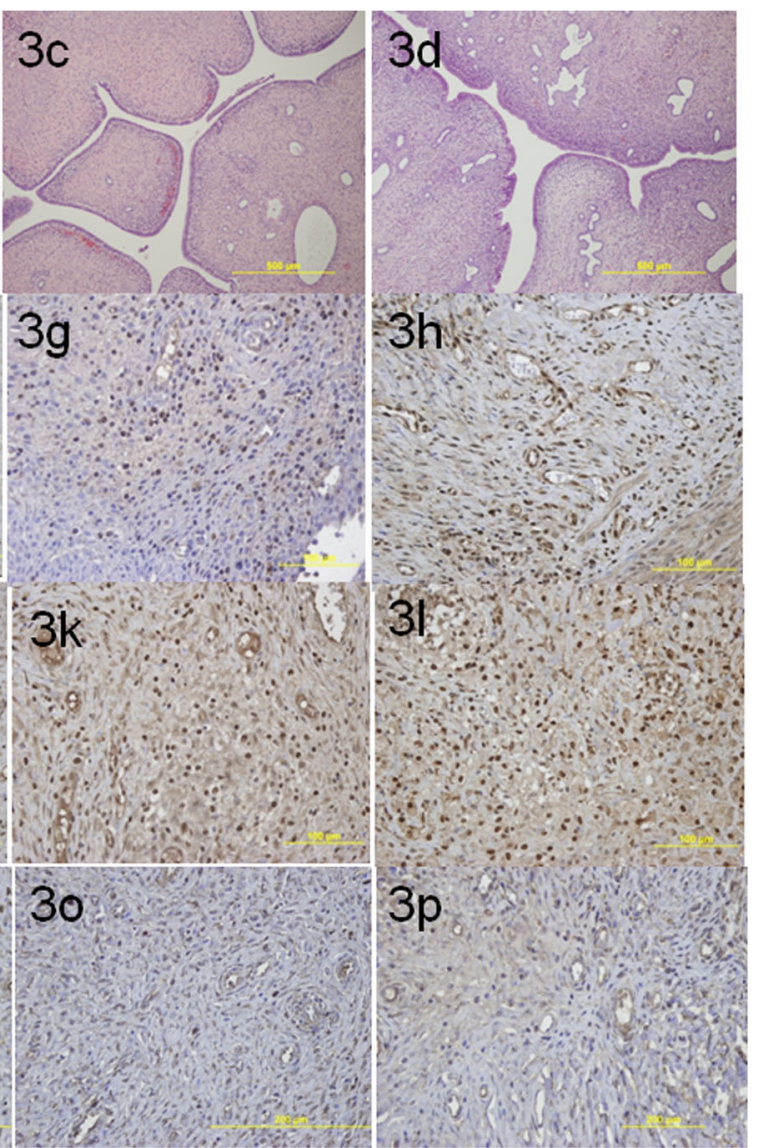

group 4. i The immunhistochemical staining of Ki-67 in group 1. $\mathbf{j}$ The immunhistochemical staining of $\mathrm{Ki}-67$ in group 2 . $\mathbf{k}$ The immunhistochemical staining of Ki-67 in group 3. I The immunhistochemical staining of Ki-67 in group 4. $\mathbf{m}$ The immunhistochemical staining of VEGF in group 1. $\mathbf{n}$ The immunhistochemical staining of VEGF in group 2. o The immunhistochemical staining of VEGF in group 3. $\mathbf{p}$ The immunhistochemical staining of VEGF in group 4

When we compared group 2 and 3; the amount of inflammation, fibrosis, vascular proliferation, PCNA and Ki-67 scores were similar. The only difference was in VEGF

Table 1 Quantitative analysis of fibrosis, inflammation, vascular proliferation and immunohistochemical analysis after light microscopic and immunhistochemical evaluation ( $p<0.05$ is considered statistically significant)

\begin{tabular}{|c|c|c|c|c|c|c|}
\hline & Fibrosis & Inflammation & Vascular proliferation & PCNA & $\mathrm{Ki}-67$ & VEGF \\
\hline Group1 & $2.55 \pm 0.73$ & $1.00 \pm 1.50$ & $0.89 \pm 0.60$ & $30.22 \pm 7.34$ & $17.33 \pm 1.66$ & $26.00 \pm 8.14$ \\
\hline Group 2 & $1.71 \pm 1.11$ & $1.29 \pm 1.11$ & $2.14 \pm 0.38$ & $52.57 \pm 5.53$ & $23.71 \pm 3.68$ & $41.42 \pm 1.99$ \\
\hline Group 3 & $0.80 \pm 0.84$ & $1.40 \pm 0.55$ & $2.60 \pm 0.55$ & $57.00 \pm 2.92$ & $26.00 \pm 5.41$ & $36.00 \pm 3.39$ \\
\hline Group 4 & $0.14 \pm 0.38$ & $0.71 \pm 0.76$ & $2.67 \pm 0.82$ & $57.86 \pm 3.48$ & $31.14 \pm 4.41$ & $44.14 \pm 13.78$ \\
\hline $\mathrm{P}$ & 0.001 & 0.509 & 0.001 & 0.000 & 0.000 & 0.003 \\
\hline G1-G2 & 0.142 & 0.536 & 0.001 & 0.000 & 0.000 & 0.005 \\
\hline G1-G3 & 0.007 & 0.364 & 0.002 & 0.001 & 0.003 & 0.019 \\
\hline G1-G4 & 0.000 & 0.918 & 0.005 & 0.000 & 0.000 & 0.016 \\
\hline G2-G3 & 0.202 & 0.876 & 0.202 & 0.268 & 0.230 & 0.005 \\
\hline G2-G4 & 0.011 & 0.383 & 0.101 & 0.026 & 0.007 & 0.026 \\
\hline G3-G4 & 0.202 & 0.149 & 0.662 & 0.639 & 0.164 & 0.048 \\
\hline
\end{tabular}

The $\mathrm{p}$ values after Mann Whitney-U tests $(p<0.05$ is considered statistically significant) 
expression which was more prominent in group 2. When we compared group 2 and group 4, less fibrosis and more Ki-67, PCNA and VEGF stainings were observed in group 4. Finally, when we compared group 3 and group 4; the only statistically significant difference was in VEGF in favor of group 4 (Table 1). When right and left uterine horns were compared; VEGF, Ki-67 and PCNA stainings were more prominent in the effected side.

\section{Discussion}

The incidence of Asherman syndrome has been rising over the last few decades due to increasing incidence of cesarean sections and uterine surgeries as well as the increased awareness and more detailed diagnostic approaches [1]. Thus, the treatment of this syndrome has also gathered a greater importance.

Despite the restoration of uterine architecture by surgery, the re-formation of adhesions and the risk of complications of these surgeries induced the need for new treatment options. There were several attempts for treatment of intrauterine synechia such as; serial flexible hysteroscopies [13], intrauterine adhesion barrier systems [14], fresh amnion graft [15], intrauterine insertion of Seprafilm [16], intrauterine devices (IUD) following hysteroscopic surgery [17, 18] and hyaluranic acid gels [19].

One of the main problem with the intrauterine filling substances is the need for the usage of concomitant antibiotics as they present a foreign body in the uterus which is in contact with the vagina and may promote infertility secondary to clinical or subclinical pelvic infections.

Today, the sequential use of high dose estrogen and progesterone is the most accepted primary method to promote endometrial healing after surgery. But the efficacy is not same in every patient. Taking into consideration of the systemic side effects with oral estrogen, some authors reported that vaginal administration of micronized estradiol was also effective in raising endometrial concentrations of estradiol [20]. But still, the patients that have contraindications for any route of administration of estrogen constitutes a problem. These problems enforced authors to continue the research for new treatment options.

The human endometrium is a dynamic tissue regenerating in every menstrual cycle. Although it is generally believed that basalis and functionalis endometrium contains the stem/progenitor cells responsible for the regenerative capacity of endometrium, there is increasing evidence that bone marrow-derived cells may also be a potential source [21].
Based on the knowledge that bone marrow-derived stem cells can differentiate into non-hematopoietic cells; a research was done in 2004 and donor-derived endometrial cells were detected in endometrial biopsy samples from all bone marrow recipients and these cells accounted for $0.2 \%$ to $48 \%$ of the epithelial cells and $0.3 \%$ to $52 \%$ of the stromal cells [22]. In another study, after bone marrow transplantation, male donorderived bone marrow cells were found in the uterine endometrium of female mice and some of these cells were found to differentiate into epithelial cells [23]. In the same year another group showed that circulating CD45+ bone marrow cells contributed more than $80 \%$ of the mouse uterine epithelium during pregnancy [24].

There is also a very recent case report in which intrauterine administration of autologous stem cells, isolated from patient's bone marrow, was shown to regenerate the endometrium and resulting in a subsequent pregnancy [25].

Based on these reports, we thought the use of stem cells for regeneration of endometrium after an experimental intrauterine synchecia model was worth trying. To our knowledge our model is the first experimental rat model for intrauterine synechia.

Considering the fact that; collection of bone marrow derived stem cells is problematic because of the invasive procedure, in our study we preferred to use a more accessible source, the adipose tissue. The recent reports showed that adipose derived stem cells (ADSCs) were similar to bone marrow derived stem cells in cell phenotype, both sources of cells have multilineage potentials, but on the proliferation rate ADSCs were faster [26].

Only the first application of ADSCs was intrauterine and the rest of applications were intra-peritoneal which was mimicking an intravenous application. The reason for the first way of application was based on the increased neutrophil activation and c-reactive protein related detrimental effects on migration, differentiation and survival of stem cells in the acute phase of damage [27].

Following the intravenous application of stem cells in the acute phase, the engraftment of these cells in the damaged area is not guaranteed. In a myocardial infarction model, the majority of the ex-vivo expanded stem cells were found to be trapped in the lung, following intravenous infusion. The same authors also indicated that direct left ventricular cavity infusion improved stem cell engraftment to the ischemic myocardium [28]. Based on the knowledge of this data, we preferred to use stem cell application directly into the damaged area instead of an intravenous route.

On the other hand; in the chronic phase; because of the decrease in the neutrophil activation and improved chemotaxis of stem cells, intrauterine application is not necessary.

To demonstrate the stimulation and proliferation of endometrium; we analyzed PCNA, Ki-67 and VEGF as markers of 
proliferation in rat uterine tissues and we found that in all treatment groups, there was a remarkable proliferation in the endometrial tissue.

A very recent report showed that ADSCs were capable of restoring the ovarian follicles and corpus lutea after induced damage of ovaries with cyclophosphamide [29]. Consistent with our immunohistochemical findings, we found that ADSCs also were as effective as estrogen in promoting endometrial proliferation. But we also found that the combination of the two methods were more effective in reducing fibrosis and improving endometrial proliferation.

The limitations of our study can be the lack of sham operation for group 2 and group 4. But our aim in this study was not the evaluation of adhesions of visceral peritoneum, but the evaluation of intrauterine adhesions. So, we believed it wouldn't add any value but would cause additional animal loss.

The power of our study is the establishment of a new experimental model for intrauterine synechia and the evidence of restorative effects of the stem cells derived from adipose tissue on regeneration of endometrial tissue without any surgical adhesiolysis.

As we know, surgery serves only to divide the adhesions within the cavity, but can do very little about the endometrial regeneration and adhesion recurrence. So women with Asherman syndrome require more than one approach to provide optimal clinical outcomes. Although stem cells are still in the research phase, the new advancing discoveries in this field are leading to new therapeutic strategies every day. We hope these findings in the present study may shed some light into the stem cell applications in reproductive medicine.

Financial support None.

Conflict of interest None.

\section{References}

1. March CM. Management of Asherman's syndrome. Reprod Biomed Online. 2011;23(1):63-76.

2. Schenker JG. Etiology of and therapeutic approach to synechia uteri. Eur J Obstet Gynecol Reprod Biol. 1996;65(1):109-13.

3. Yu D, Wong YM, Cheong Y, Xia E, Li TC. Asherman syndromeone century later. Fertil Steril. 2008;89:759-79.

4. Foix A, Bruno RO, Davison T, Lema B. The pathology of postcurettage intrauterine adhesions. Am J Obstet Gynecol. 1966;96(7):1027-33.

5. March CM. Intrauterine adhesions. Obstet Gynecol Clin North Am. 1995;22(3):491.

6. Yuksel B, Kilic S, Taser F, Pinarli F, Delibasi T. Male fertility preservation, current options with stem cells. Niche. 2012;1:42-5.

7. Sliwiński L, Folwarczna J, Nowińska B, Cegieła U, Pytlik M, Kaczmarczyk-Sedlak I, et al. A comparative study of the effects of genistein, estradiol and raloxifene on the murine skeletal system. Acta Biochim Pol. 2009;56(2):261-70.

8. Fried SK, Moustaid-Moussa N. Culture of adipose tissue and isolated adipocytes. Methods Mol Biol. 2001;155:197-212.

9. Irkorucu O, Ferahköșe Z, Memiș L, Ekinci O, Akin M. Reduction of postsurgical adhesions in a rat model: a comparative study. Clinics (Sao Paulo). 2009;64(2):143-8.

10. Yokoyama Y, Takahashi Y, Morishita S, Hashimoto M, Niwa $\mathrm{K}$, Tamaya $\mathrm{T}$. Telomerase activity in the human endometrium throughout the menstrual cycle. Mol Hum Reprod. 1998;4(2): 173-7.

11. McCampbell AS, Walker CL, Broaddus RR, Cook JD, Davies PJ. Developmental reprogramming of IGF signaling and susceptibility to endometrial hyperplasia in the rat. Lab Invest. 2008;88(6):615-26.

12. Li X, Sun H, Lin N, Hou X, Wang J, Zhou B, et al. Regeneration of uterine horns in rats by collagen scaffolds loaded with collagenbinding human basic fibroblast growth factor. Biomaterials. 2011;32(32):8172-81.

13. Robinson JK, Colimon LM, Isaacson KB. Postoperative adhesiolysis therapy for intrauterine adhesions (Asherman's syndrome). Fertil Steril. 2008;90(2):409-14.

14. Abbott J, Thomson A, Vancaillie T. SprayGel following surgery for Asherman's syndrome may improve pregnancy outcome. J Obstet Gynaecol. 2004;24(6):710-1.

15. Amer MI, Abd-El-Maeboud KH. Amnion graft following hysteroscopic lysis of intrauterine adhesions. J Obstet Gynaecol Res. 2006;32(6):559-66.

16. Tsapanos VS, Stathopoulou LP, Papathanassopoulou VS, Tzingounis VA. The role of Seprafilm bioresorbable membrane in the prevention and therapy of endometrial synechiae. J Biomed Mater Res. 2002;63(1):10-4.

17. Polishuk WZ, Adoni A, Aviad I. Intrauterine device in the treatment of traumatic intrauterine adhesions. Fertil Steril. 1969;20(2):241-9.

18. Orhue AA, Aziken ME, Igbefoh JO. A comparison of two adjunctive treatments for intrauterine adhesions following lysis. Int J Gynaecol Obstet. 2003;82(1):49-56.

19. Lin X, Wei M, Li TC, Huang Q, Huang D, Zhou F, et al. A comparison of intrauterine balloon, intrauterine contraceptive device and hyaluronic acid gel in the prevention of adhesion reformation following hysteroscopic surgery for Asherman syndrome: a cohort study. Eur J Obstet Gynecol Reprod Biol. 2013;S0301-2115(13): 00325-4.

20. Tourgeman D, Gentzchein E, Stanczyk FZ, Paulson RJ. Serum and tissue hormone levels of vaginally and orally administered estradiol. Am J Obstet Gynecol. 1999;180:1480-3.

21. Gargett CE, Masuda H. Adult stem cells in the endometrium. Mol Hum Reprod. 2010;16(11):818-34.

22. Taylor HS. Endometrial cells derived from donor stem cells in bone marrow transplant recipients. JAMA. 2004;292(1):81-5.

23. Du H, Taylor HS. Contribution of bone marrow-derived stem cells to endometrium and endometriosis. Stem Cells. 2007;25(8):2082-6.

24. Bratincsák A, Brownstein MJ, Cassiani-Ingoni R, Pastorino S, Szalayova I, Tóth ZE, et al. CD45-positive blood cells give rise to uterine epithelial cells in mice. Stem Cells. 2007;25(11):2820-6.

25. Nagori CB, Panchal SY, Patel H. Endometrial regeneration using autologous adult stem cells followed by conception by in vitro fertilization in a patient of severe Asherman's syndrome. J Hum Reprod Sci. 2011;4(1):43-8.

26. Zhu X, Shi W, Tai W, Liu F. The comparition of biological characteristics and multilineage differentiation of bone marrow and adipose derived Mesenchymal stem cells. Cell Tissue Res. 2012;350(2):27787. 
27. Wu J, Li J, Zhang N, Zhang C. Stem cell-based therapies in ischemic heart diseases: a focus on aspects of microcirculation and inflammation. Basic Res Cardiol. 2011;106(3):317-24.

28. Barbash IM, Chouraqui P, Baron J, Feinberg MS, Etzion S, Tessone A, et al. Systemic delivery of bone marrow-derived mesenchymal stem cells to the infarcted myocardium: feasibility, cell migration, and body distribution. Circulation. 2003;108(7):863-8.

29. Takehara Y, Yabuuchi A, Ezoe K, Kuroda T, Yamadera R, Sano C, et al. The restorative effects of adipose-derived mesenchymal stem cells on damaged ovarian function. Lab Invest. 2013;93(2):181-93. 